\title{
Síntesis y actualización de los instrumentos del algoritmo David Liberman y ejemplificación de aplicaciones combinadas
}

\section{Synthesis and actualization of David Liberman Algorithm (DLA) as method of clinical investigation}

\author{
David Maldavsky* \\ Universidad de Ciencias Empresariales y Sociales, Argentina
}

(Rec.: diciembre de 2014 - Acept.: abril de 2016)

\begin{abstract}
Resumen
El autor describe los instrumentos del algoritmo David Liberman (ADL) para los estudios clínicos y psicosociales. Los conceptos centrales son deseo y defensa (y su estado), y los niveles de análisis abarcan el terreno de lo verbal (relatos, actos de habla, palabras) y de lo no verbal (lo motriz, lo visual, lo fonológico). Se describen sintéticamente los instrumentos y algunos de los procedimientos, y se agregan tres ejemplos de investigaciones en que se aplicaron varios de estos instrumentos.
\end{abstract}

Palabras clave: deseo, defensa, verbalizaciones, aspectos no verbales, combinación entre instrumentos.

\begin{abstract}
The author describes the instruments related to David Liberman`s algorithm (DLA) for clinical and psychosocial studies. The main concepts are wish and defense (and their state), and the levels of analysis include both verbal (stories, speech acts and words) and non-verbal expression (motor, visual, phonological). The instruments, some of the procedures, and three research studies (in which various DLA tools were applied), are summarized.
\end{abstract}

Keywords: wish, defense, verbalizations, non-verbal expressions, tools combination.

\footnotetext{
* Correspondencia a: David Maldavsky. República Árabe Siria 3319, 5B, Buenos Aires, Argentina. C.P.: 1425. E-mail: dmaldavsky@gmail.com
} 
Para encarar la compleja realidad psíquica desarrollamos instrumentos basados en los mismos conceptos (deseo y defensa y su estado), aptos para realizar análisis en los terrenos verbal y no verbal, y aptos también para realizar combinaciones entre ellos en estudios concretos. En el terreno verbal, los instrumentos estudian la palabra, los actos de habla y los relatos. En el terreno no verbal, estudian los desempeños motrices, los componentes paraverbales y las expresiones visuales en sus aspectos icónico y plástico.

\section{Conceptos}

Los conceptos centrales son pulsión (y el deseo, su derivado) y defensa (y su estado) que Freud expuso en numerosos trabajos. Psicoanalistas de diferentes orientaciones destacaron la relevancia de la pulsión (y del deseo) como empuje o fuente motivacional. Entre las pulsiones, las sexuales tienen fuerte peso en las manifestaciones.

Propusimos este repertorio de las pulsiones (y los deseos correspondientes): 1) libido intrasomática (LI), 2) oral primaria $(\mathrm{O} 1), 3)$ sádico-oral secundaria (O2), 4) sádico-anal primaria (A1), 5) sádico-anal secundaria $(A 2), 6)$ fálico-uretral $(F U), 7)$ fálico-genital $(F G)$. El concepto LI fue solo mencionado por Freud (1926) cuando sostuvo que en el comienzo de la vida post-natal la investidura recae sobre ciertos órganos internos, sobre todo corazón y pulmones. Las pulsiones suelen enlazarse con representaciones, con huellas mnémicas (entre ellas las motrices, visuales y verbales), y en consecuencia se transforman en deseos.

Freud (1915) consideró a las defensas destinos de las pulsiones (y los deseos), es decir, modos de procesamiento psíquico de los conflictos de estas con la realidad y con una instancia valorativa y crítica, el superyó. En el conflicto a veces la defensa opera en favor de alguna de las orientaciones en pugna. Las defensas patológicas generan un creciente empobrecimiento en la vida psíquica y las funcionales una creciente diferenciación y complejización (Maldavsky, 2013). El repertorio de las defensas funcionales y patológicas puede ordenarse por el grado decreciente de conciliación entre los sectores en pugna. Entre las funcionales figuran: 1) acorde a fines, 2) inhibición, 3) creatividad, 4) sublimación, y entre las patológicas: 1) represión, 2) represión con rasgos caracterológicos, 3) desmentida, 4) desestimación de la realidad y la instancia paterna, 5) desestimación del afecto. En algunos contextos, una defensa patológica puede ser empleada funcionalmente, como la desmentida que desarrollan pacientes terminales, que aprovechan la vida pese a su estado. Los deseos se combinan con todas las defensas funcionales, y cada deseo se combina con un grupo restringido de defensas patológicas. Además, Freud (1915) sostuvo que las manifestaciones clínicas derivan del fracaso de la defensa, y no su éxito. Las defensas tienen dos aspiraciones complementarias: mantener el equilibrio narcisista, el sentimiento de sí, que es lo central, y rechazar algo desequilibrante fuera del yo, que es el medio para alcanzarlo. La defensa exitosa implica que se ha logrado rechazar algo y que se mantiene o incrementa el sentimiento de sí, la fracasada implica el retorno de eso rechazado y la emergencia de la angustia. Mientras que la situación mixta (defensa exitoso/fracasada) implica que, haya retornado o no lo rechazado, no se mantiene el sentimiento de sí, sino una condición más bien neutra. En consecuencia, el estado de una defensa es exitoso, fracasado o mixto. He aquí una perspectiva que combina deseo, defensa y estado (Tabla 1).

Tabla 1. Combinaciones entre deseos, defensas y estados

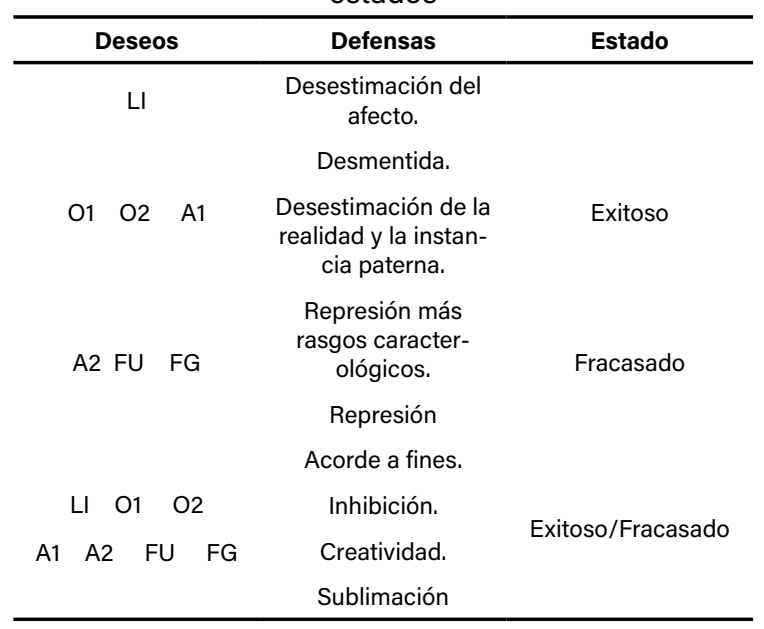

El algoritmo David Liberman (ADL en adelante) permite estudiar el cambio clínico en el paciente, en el terapeuta o en el vínculo. El estudio del cambio clínico en el paciente requiere considerar las defensas y su estado. El cambio clínico positivo suele consistir en la sustitución de defensas patológicas por otras más benignas. El cambio clínico en el terapeuta suele consistir en un cambio en la táctica y estrategia de sus intervenciones, que pueden ser estudiadas en cuanto a la función y el estilo. El cambio clínico positivo en el vínculo consiste en el afianzamiento de la alianza terapéutica, una atenuación de las resistencias del paciente y un creciente acierto en la función y el estilo de las intervenciones del terapeuta .

El ADL permite también estudiar deseos, valores, espacialidades, etc., en manifestaciones psicosociales de variado tipo.

\section{Niveles de análisis de las manifestaciones}

Es posible estudiar deseos y defensas en manifestaciones verbales, motrices, paraverbales y visuales. En el terreno verbal pueden estudiarse la palabra, el 
acto de habla y el relato. Existen dos estrategias de análisis que pueden o no combinarse, una macro y otra micro-analítica. La primera conduce a estudiar escenas, mientras que la micro-analítica no necesariamente permite estudiar escenas, pero sí inferirlas. Las escenas pueden ser relatadas o desplegadas, es decir, desarrolladas en el acto de la manifestación, verbal o no verbal: una persona puede relatar escenas de evitación en sus vínculos y manifestar esto mismo en sus actos de habla, con numerosas muletillas (del tipo "esteee"), diminutivos que atenúan un contacto ("casi enojado"), una atenuación del volumen de voz, sonidos sibilantes (cuchicheo) o una mirada huidiza. Las escenas relatadas y las desplegadas pueden ser estudiadas con los instrumentos para el nivel macro (análisis de relatos, de actos de habla, de componentes fonológicos, de la motricidad y de las expresiones gráficas). En el nivel micro-analítico se encuentran los estudios de las palabras y de algunos componentes plásticos del signo visual.

En el terreno verbal, el análisis de los deseos y las defensas (y su estado) en los relatos permite detectar las escenas del paciente fuera de la sesión, en el mundo de su cotidianeidad. El análisis de los deseos y las defensas (y su estado) en los actos de habla, en cambio, permite estudiar las escenas que el paciente despliega en la sesión misma. A su vez, el análisis de los deseos en las palabras permite acceder a algunas escenas que a veces coinciden con las desplegadas o relatadas $y$, a veces, no han llegado a expresarse ni en los relatos ni a desplegarse en el curso de la sesión. Se trata de tres niveles de análisis, de lo macro a lo microscópico .

A su vez, el análisis en el nivel no verbal (motricidad, fonación, imágenes visuales) permite detectar las escenas que el paciente despliega en la sesión, y en este sentido, suelen formar parte de un mismo conjunto con los actos de habla. Sin embargo, sobre todo las imágenes visuales, en particular el componente icónico, pueden ser también un modo de relatar una escena. La escena desplegada en una sesión puede tener múltiples matices, no necesariamente coincidentes. Así, por ejemplo, puede ser que determinados actos de habla de acusación sean proferidos con una voz aguda y chillona, o que determinados actos de habla histriónicos se combinen con eructos o chasquidos de lengua. Cuando se dan discordancias entre los actos de habla y los componentes fonológicos o motrices, es conveniente dar prevalencia a lo expresado por estos últimos (componentes fonológicos o motrices).

\section{Instrumentos para el análisis de las manifestaciones verbales}

Instrumentos para el análisis de deseos y defensas
en los relatos (ADL-R) (Maldavsky, 2013)

Los instrumentos para analizar relatos consisten en 1) una grilla para estudiar las escenas relatadas; 2) una grilla con una descripción de espacios, ideales, personajes, etc., para cada deseo; 3) una distribución de frecuencias de los deseos en los relatos de los pacientes; 4) instrucciones para que el investigador decida, a partir del análisis de deseos, cuáles son las defensas dominantes y su estado. Solo expondremos aquí la grilla (Tabla 2) para estudiar el deseo en las escenas relatadas.

Se presentan cinco momentos, de los cuales dos son estados (inicial y final) y tres son transformaciones (despertar del deseo, tentativa de consumarlo, consecuencias de ello). Este relato es ideal, en la práctica se suele presentar fragmentado: las consecuencias de la tentativa de consumar el deseo y el estado final, por ejemplo. La grilla tiene doble entrada: cada deseo se combina con los cinco momentos (estado inicial, despertar del deseo, etc.).

El ADL-R propone transformar las transcripciones de las sesiones en términos de secuencias narrativas. En ellas se combinan hasta tres escenas que se ajustan a dos criterios: isotopía y enlace cronológico-causal. Las escenas que componen una misma secuencia narrativa pueden ser expresiones del mismo o de diferentes deseos. Existen también instrucciones para decidir sobre el valor de cada deseo cuando se obtienen resultados multivariados.

\section{Instrumentos para el análisis de deseos y defensas en los actos de habla (ADL-AH) (Maldavsky, 2013)}

Los instrumentos para el estudio de deseos y defensas en los actos del habla son: 1) una grilla con la caracterización de actos de habla para cada deseo; 2) distribuciones de frecuencias de los deseos en los actos de habla de pacientes, de terapeutas y de textos periodísticos; 3) instrucciones para que el investigador decida, a partir del análisis de deseos, cuáles son las defensas dominantes y su estado en paciente y terapeuta. Solo expondremos aquí algunos actos de habla de la grilla para estudiar el deseo en las escenas desplegadas: dedicatoria y promesa, para FG; refranes y consejos, para FU; enlaces causales y objeciones, para A2; ofensas y amenazas, para $A 1$; lamentos y ruegos, para $\mathrm{O} 2$; lenguaje cifrado, en clave, y metalenguaje, para O1; cuentas y banalizaciones, para LI.

Existe, además, una categorización de las intervenciones clínicas del terapeuta según su función: 1) introductorias (saludos, recabar información); 2) centrales (que apuntan a sintonizar con los estados corporales o afectivos del paciente y a establecer nexos causales, de semejanza, etc.) y 3) complementarias (ejemplificaciones, síntesis, aclaraciones). Es posible combinar ambos estudios (deseos y funciones) respecto del discurso del terapeuta.

Los procedimientos corresponden a un enfoque para- 
Tabla 2. Deseos y relatos

\begin{tabular}{|c|c|c|c|c|c|c|c|}
\hline $\begin{array}{c}\text { DESEO } \\
\text { ESCENA }\end{array}$ & FG & FU & A2 & A1 & 02 & 01 & LI \\
\hline $\begin{array}{l}\text { Estado } \\
\text { inicial }\end{array}$ & $\begin{array}{l}\text { Armonía } \\
\text { estética }\end{array}$ & Rutina & $\begin{array}{l}\text { Orden } \\
\text { jerárquico }\end{array}$ & $\begin{array}{c}\text { Equilibrio } \\
\text { jurídico } \\
\text { natural }\end{array}$ & Paraíso & $\begin{array}{l}\text { Paz cogni- } \\
\text { tiva }\end{array}$ & $\begin{array}{c}\text { Equilibrio } \\
\text { de ten- } \\
\text { siones }\end{array}$ \\
\hline $\begin{array}{l}\text { Primera } \\
\text { trasfor- } \\
\text { mación: } \\
\text { despertar } \\
\text { del Deseo }\end{array}$ & $\begin{array}{l}\text { Deseo de } \\
\text { completud } \\
\text { estética }\end{array}$ & $\begin{array}{l}\text { Deseo } \\
\text { ambici- } \\
\text { oso }\end{array}$ & $\begin{array}{l}\text { Deseo de } \\
\text { dominar a } \\
\text { un objeto } \\
\text { en el marco } \\
\text { de un } \\
\text { juramento } \\
\text { público }\end{array}$ & $\begin{array}{l}\text { Deseo } \\
\text { justiciero }\end{array}$ & $\begin{array}{l}\text { Tentación } \\
\text { Expiación }\end{array}$ & $\begin{array}{c}\text { Deseo } \\
\text { cognitivo } \\
\text { abstracto }\end{array}$ & $\begin{array}{l}\text { Deseo } \\
\text { especu- } \\
\text { latorio }\end{array}$ \\
\hline $\begin{array}{l}\text { Segunda } \\
\text { trasfor- } \\
\text { mación: } \\
\text { tentativa } \\
\text { de con- } \\
\text { sumar el } \\
\text { deseo }\end{array}$ & $\begin{array}{c}\text { Recep- } \\
\text { ción de un } \\
\text { don-regalo }\end{array}$ & $\begin{array}{c}\text { En- } \\
\text { cuentro } \\
\text { con } \\
\text { una } \\
\text { marca } \\
\text { paterna } \\
\text { en el } \\
\text { fondo } \\
\text { del } \\
\text { objeto }\end{array}$ & $\begin{array}{c}\text { Dis- } \\
\text { cernimiento } \\
\text { de que el } \\
\text { objeto es } \\
\text { fiel a suje- } \\
\text { tos corrup- } \\
\text { tos }\end{array}$ & Venganza & $\begin{array}{c}\text { Pecado } \\
\text { Reparación }\end{array}$ & $\begin{array}{c}\text { Acceso a } \\
\text { una verdad }\end{array}$ & $\begin{array}{c}\text { Ganancia } \\
\text { de goce } \\
\text { por la } \\
\text { intrusión } \\
\text { orgánica }\end{array}$ \\
\hline \multirow{2}{*}{$\begin{array}{l}\text { Tercera } \\
\text { trasfor- } \\
\text { mación: } \\
\text { conse- } \\
\text { cuencias } \\
\text { de la ten- } \\
\text { tativa de } \\
\text { consumar } \\
\text { el deseo }\end{array}$} & \multirow{2}{*}{$\begin{array}{l}\text { Embarazo } \\
\text { o equiv- } \\
\text { alente de } \\
\text { enriquec- } \\
\text { imiento y } \\
\text { plenitud } \\
\text { estéticos }\end{array}$} & $\begin{array}{l}\text { Desafío } \\
\text { aven- } \\
\text { turero }\end{array}$ & $\begin{array}{l}\text { Reconoci- } \\
\text { miento por } \\
\text { su virtud }\end{array}$ & $\begin{array}{c}\text { Con- } \\
\text { sagración } \\
\text { y reconoci- } \\
\text { miento del }\end{array}$ & $\begin{array}{l}\text { Expulsión } \\
\text { del Paraíso }\end{array}$ & $\begin{array}{l}\text { Reconoci- } \\
\text { miento de } \\
\text { la geniali- } \\
\quad \text { dad }\end{array}$ & $\begin{array}{l}\text { Euforia } \\
\text { orgánica }\end{array}$ \\
\hline & & $\begin{array}{l}\text { Desafío } \\
\text { rutinar- } \\
\quad \text { io }\end{array}$ & $\begin{array}{l}\text { Condena } \\
\text { social y } \\
\text { expulsión } \\
\text { moral }\end{array}$ & $\begin{array}{l}\text { Impotencia } \\
\text { motriz, } \\
\text { encierro } \\
\text { y Humil- } \\
\text { lación }\end{array}$ & $\begin{array}{l}\text { Recono- } \\
\text { cimiento } \\
\text { amoroso }\end{array}$ & $\begin{array}{c}\text { Pérdida de } \\
\text { lucidez } \\
\text { para el } \\
\text { goce cogni- } \\
\text { tivo ajeno }\end{array}$ & \\
\hline \multirow{3}{*}{$\begin{array}{l}\text { Estado } \\
\text { final }\end{array}$} & $\begin{array}{l}\text { Armonía } \\
\text { compartida }\end{array}$ & $\begin{array}{l}\text { Aven- } \\
\text { tura }\end{array}$ & Paz moral & $\begin{array}{l}\text { Evocación } \\
\text { del pasado } \\
\text { heroico }\end{array}$ & $\begin{array}{l}\text { Valle de } \\
\text { lágrimas }\end{array}$ & $\begin{array}{l}\text { Goce en la } \\
\text { revelación }\end{array}$ & \multirow{3}{*}{$\begin{array}{c}\text { Equi- } \\
\text { librio de } \\
\text { tensiones } \\
\text { sin pér- } \\
\text { dida de } \\
\text { energía }\end{array}$} \\
\hline & $\begin{array}{l}\text { Sentimiento } \\
\text { duradero de } \\
\text { Asquerosi- } \\
\text { dad }\end{array}$ & $\begin{array}{l}\text { Rutina } \\
\text { pesi- } \\
\text { mista }\end{array}$ & $\begin{array}{c}\text { Tormento } \\
\text { moral }\end{array}$ & $\begin{array}{l}\text { Retorno } \\
\text { a la paz } \\
\text { natural }\end{array}$ & $\begin{array}{l}\text { Recuper- } \\
\text { ación del } \\
\text { Paraíso }\end{array}$ & $\begin{array}{l}\text { Pérdida de } \\
\text { la esencia }\end{array}$ & \\
\hline & & & & $\begin{array}{l}\text { Resen- } \\
\text { timiento } \\
\text { duradero }\end{array}$ & & & \\
\hline
\end{tabular}


digmático (donde se reúnen los actos de habla pertenecientes a cada grupo y se extraen porcentajes, etc.) o sintagmático (en el que se valora cada acto de habla en el contexto concreto de las manifestaciones).

\section{Instrumentos para el análisis de deseos en las pala-} bras (ADL-P) (Maldavsky, 2013)

Los instrumentos del ADL para el estudio de palabras consisten en un diccionario computarizado de alrededor de 650.000 palabras (unas 5.000 radicales), que categoriza palabras por deseo y una distribución de frecuencias de deseos en las palabras de pacientes, terapeutas, textos periodísticos, discursos papales y presidenciales. Solo expondremos aquí algunos sustantivos para cada deseo: para FG, adoración, afeamiento, joya, regalo; para FU, ambición, influencia, mapa, suerte; para $A 2$, desaseo, organización, respeto, tenacidad; para $A 1$, aburrimiento, desafío, fiscales, ofensa; para O2, cariño, agradecimiento, desamor, sacrificio; para O1, adivinanza, filosofía, fórmula, enigma; para LI, ganancia, porcentajes, riñón, somnolencia.

En cuanto a los procedimientos, se prepara la muestra para eliminar comentarios agregados, completar palabras, etc.

Nota: los instrumentos para el análisis del discurso verbal van acompañados de instrumentos complementarios, entre ellos, las distribuciones de frecuencias en los tres niveles de análisis para las manifestaciones de los pacientes y de los terapeutas.

\section{Instrumentos para el análisis de las manifestaciones no verbales}

\section{Instrumentos para el análisis de deseos y defensas en los desempeños motrices (ADL-M) (Maldavsky, 2014c)}

Los instrumentos para el análisis de los desempeños motrices consisten en una grilla para estudiar escenas desplegadas en los programas gesticulares; una grilla con una descripción de distancias inter-individuales, según cada deseo; instrucciones para que el investigador decida, a partir del análisis de los deseos, cuáles son las defensas dominantes y su estado. El estudio del deseo en los programas gesticulares requiere considerar que cada movimiento concreto se inserta en diferentes conjuntos de secuencias (Greimas, 1973). Además pueden estudiarse la tonicidad y la velocidad.

Solo expondremos algunos rasgos de cada programa gesticular expresado como tendencia: para FG, totalización estética; para $\mathrm{FU}$, penetrar; para $\mathrm{A} 2$, aferrar y dominar; para A1, venganza; para $\mathrm{O} 2$, expresión de sentimientos; para 01, extracción de una esencia o líquido, o de una clave abstracta (empleando dedos, lengua, ojos); para LI, alteración interna (como en los procedimientos autocalmantes).
Los procedimientos corresponden a un enfoque macro o microanalítico. El cuerpo suele no ser una unidad sino un conjunto de programas gesticulares, tonicidades y ritmos.

Instrumentos para el análisis de deseos y defensas en los signos visuales (ADL-SV) (Maldavsky, 2014a, 2015a)

Los instrumentos para el análisis de deseos abarcan el terreno icónico y el plástico (Ėdeline, Klinkenberg \& Minguet, 1993). Los instrumentos para el estudio de los deseos en los signos visuales consisten en grillas para estudiar componentes icónicos; grillas para estudiar componentes plásticos; instrucciones para que el investigador decida, a partir del análisis de los deseos, cuáles son las defensas dominantes y su estado.

Las grillas para el estudio de deseos en el componente icónico visual son las empleadas para el análisis de relatos: estudio de escenas (acciones o estados), los complementos de estas escenas (objetos, atributos); y para el estudio de desempeños motrices y distancias. Las grillas para el estudio de deseos en el componente plástico corresponden a instrumentos que enfocan la forma (distribución y orientación de la imagen, tamaños relativos de las imágenes, distancias, configuración del mundo sensible, rasgos de las líneas y trazo de las líneas), el color (componente cromático y luminosidad) y las texturas. Por ejemplo, en la grilla para el estudio de los deseos, en los rasgos de la línea figuran: para FG, curva; para FU, ascendente, con huecos en el ápice y luego descendente; para $\mathrm{A} 2$, con ángulos rectos; para $A 1$, alternancia entre líneas gruesas y delgadas; para 02 , gruesa, bordes gruesos con ángulos excesivamente agudos; para 01 , tenue, compás, regla, doble línea, líneas de puntos o de rayas pequeñas; para $\mathrm{LI}$, gruesa o extremadamente delgada.

Suele resultar conveniente elegir alguna grilla, como la referente al color, cuando se estudian manchas cromáticas. Cuando existen contradicciones entre los resultados de los análisis en el terreno icónico y en el plástico, sugerimos tomar este último resultado como dominante, y los correspondientes al terreno icónico como subordinados.

Instrumentos para el análisis de deseos y defensas en el componente fonológico (ADL-CF) (Maldavsky et al., 2007)

Los instrumentos para el análisis de deseos en los componentes paraverbales consisten en una grilla para estudiar las escenas desplegadas en la fonación; una correlación entre alturas e intensidades de los sonidos vocales y estados afectivos; un conjunto de instrucciones para que el investigador decida, a partir del análisis de los deseos, cuáles son las defensas dominantes y su estado. Expondremos un segmento de la grilla para estudiar el deseo en las escenas desple- 
gadas en la fonación y una síntesis de la relación entre alturas sonoras, afectos y defensas. En la grilla figuran estos tonos: seductor y declamatorio para FG; pesimista y desconfiado para FU; admonitorio e imperativo para A2; acusatorio y burlón para A1; impaciente y maníaco para O2; metálico y desafecto para O1; apático y somnoliento para LI. En la grilla se toman en cuenta el tono, la altura y el timbre y sus variaciones.

El estudio de alturas e intensidades de los sonidos de un hablante requiere de un analizador acústico. En el terreno tonal, destacamos una relación entre determinadas alturas, los estados afectivos de angustia o de tristeza y las defensas implementadas.

La grilla es aplicable sobre todo en investigaciones cualitativas, mientras que el instrumento que mide alturas y tonos es apto en estudios micro-analíticos, cuantitativos o cuali-cuantitativos.

\section{Aplicaciones de las combinaciones entre instrumentos}

Expondremos sintéticamente tres investigaciones, dos clínicas y una psicosocial, en las que aplicamos varios instrumentos (con un grado creciente de complejidad en la combinación entre instrumentos) a las muestras.

Estudio l. Análisis de las intervenciones de los deseos en las palabras de un terapeuta en la primera sesión con 20 pacientes diferentes (Maldavsky et al., 2016).

Combinamos dos instrumentos: la categorización de las intervenciones del terapeuta según su función y el ADL-P. Esto, con el agregado de las distribuciones de frecuencias de los deseos en las palabras del terapeuta, con la siguiente secuencia de procedimientos. En primer lugar, categorizamos la función de las intervenciones del terapeuta, para lo cual cuatro investigadores entrenados, distribuidos en dos equipos, discutieron entre sí y resolvieron las diferencias por consenso, con un tercer investigador que dirimía los desacuerdos subsistentes. En segundo lugar, determinamos el porcentaje de las funciones de las intervenciones en cada uno de los tres tercios en las sesiones. Finalmente, investigamos los deseos en los tipos de intervenciones.

Desarrollamos tres estudios: 1) el porcentaje de las funciones de las intervenciones del terapeuta a lo largo de la hora distribuida en tercios; 2) el percentil de los deseos según los tipos de intervenciones a lo largo de la hora; 3 ) las variaciones en cuanto a los deseos en cada tipo de intervención en tercios.

Como resultado, el primer estudio muestra que, a medida que avanza la sesión, disminuyen las intervenciones introductorias y de sintonía y se incrementan las de nexo y las complementarias. El segundo muestra los deseos expresados en cada tipo de intervención.
Se observa que en cada tipo de intervención tienen alguna relevancia ciertos deseos. De este modo, podemos observar el alto valor de A2 en las intervenciones introductorias (como expresión de la tentativa del terapeuta de obtener información concreta sobre el consultante); el valor medio-alto de $\mathrm{O} 2$ en las intervenciones centrales de sintonía (como expresión del énfasis en los estados afectivos del paciente); el peso de 01 y A2 en las intervenciones centrales de nexo (el primero como expresión de la tendencia a un cierto grado de abstracción, y el segundo de la tendencia a la producción de conexiones causales); los relativamente bajos valores de $\mathrm{O} 2$ (como indicador de la atenuación del énfasis del terapeuta en los estados afectivos del paciente) y la relevancia de $\mathrm{O} 1$ en las intervenciones complementarias (que parece continuar la orientación a la generalización y la abstracción de las intervenciones centrales de nexo). Estos rasgos parecen acordes a la actividad terapéutica específica en cada momento.

El tercer estudio aporta un panorama de las variaciones en los tipos de intervenciones y los deseos del terapeuta durante la sesión. Estas variaciones parecen acordes a los tipos de intervenciones. De este modo, es palpable la tendencia a aludir cuestiones económicas y/o corporales en las intervenciones de nexo; a pensar abstractamente en las intervenciones introductorias y de nexo; a describir estados afectivos en las de sintonía, a incluir partículas aumentativas en las intervenciones de sintonía y a la disminución del control y del orden en las intervenciones de sintonía y en las de nexo. Parecería que con el avance de la sesión el terapeuta recurre a intervenciones más precisas y acordes con las metas clínicas.

En suma, el primer estudio muestra los cambios en los tipos de intervenciones del terapeuta a medida que la sesión avanza, el segundo estudio muestra los rasgos expresivos del terapeuta al formular uno u otro tipo de intervención y el tercer estudio muestra algunos cambios en dichos rasgos expresivos a medida que la sesión avanza y varía la ocurrencia en los tipos de intervenciones.

\section{Estudio II: Análisis de la perturbación contratransfe- rencial (Maldavsky, 2015b).}

El concepto alude a las interferencias clínicas por el influjo que el paciente ejerce sobre su sentir inconsciente, declarado o no por el terapeuta. Los objetivos del estudio son, en primer lugar, desarrollar un método y un procedimiento para el estudio empírico de la contratransferencia duradera $y$, en segundo lugar, aplicar el método a una muestra de 8 sesiones.

Operacionalizar el concepto requiere considerar dos aspectos: la perturbación en el trabajo clínico; los procesos psíquicos perturbadores en el terapeuta, derivados del intercambio con el paciente. 
La perturbación contratransferencial duradera se caracteriza por las intervenciones clínicamente no pertinentes y/o las estrategias clínicas no adecuadas. El trabajo terapéutico no pertinente se presenta en intervenciones introductorias, por la dispersión en la búsqueda de información para localizar y precisar los focos problemáticos, o por la irrupción prematura de una intervención central de establecimiento de nexos. También se encuentra presente en intervenciones tendientes a sintonizar con el paciente, en las cuales el terapeuta colige un estado afectivo cuando lo central es un estado orgánico del paciente. Del mismo modo, se manifiesta en la no elección del foco del conflicto remplazado por algún otro aspecto mencionado por el paciente, o en el establecimiento incorrecto de los nexos causales no acordes con la realidad psíquica del paciente. Finalmente, el trabajo terapéutico no pertinente también se expresa a través de intervenciones complementarias, si la síntesis o la ejemplificación contradicen lo central de las intervenciones previas. Es frecuente que se presenten dos estrategias clínicas, una pertinente y otra no.

Las perturbaciones contratransferenciales se expresan también en la formulación de las intervenciones (en los componentes paraverbales o en los actos de habla). Esto es, contradicciones entre decir y hacer, inclusión de alto número de frases en suspenso, dramatizaciones, etc. Esta segunda perspectiva permite detectar el factor eficaz: los procesos psíquicos del terapeuta, derivados del intercambio con el paciente. Puede detectarse que el terapeuta desplegó una escena del mundo psíquico que el paciente expresó en alguna escena relatada o desplegada. En esta escena que el terapeuta desarrolla inadvertidamente se evidencian deseos y defensas perturbadoras y a veces defensas secundarias frente a estos procesos.

El análisis de deseos y defensas en relatos y actos de habla del paciente permite detectar el fracaso de una defensa, funcional o patológica, y en consecuencia, los conflictos irresueltos del paciente. Esto resulta orientador para el establecimiento del foco. El estado del paciente se infiere de las escenas relatadas recientes y de las desplegadas en la sesión. Con ello disponemos de recursos para evaluar la pertinencia de las intervenciones del terapeuta referidas a foco, sintonía y establecimiento de nexos.

El estudio de las perturbaciones de contratransferencia en las escenas desplegadas por el terapeuta implica considerar el nexo entre estas escenas y los relatos realizados por el paciente y/o las escenas que desarrolla con sus actos de habla. Este estudio permite determinar si el terapeuta despliega inadvertidamente la posición de un personaje de la vida psíquica del paciente, o se ha puesto en el lugar del paciente mismo, como expresión de sus deseos y defensas perturbadores.
Los instrumentos para el estudio de los deseos y las defensas (y su estado exitoso, fracasado, mixto) son: el ADL-R para los relatos del paciente; el ADL-H, para las escenas desplegadas por paciente y terapeuta y la categorización de las intervenciones clínicas del ADL (Maldavsky, 2013).

Los procedimientos conducen a detectar, por una parte, intervenciones clínicamente no pertinentes, y por otra, procesos inconscientes perturbadores en el terapeuta y el influjo del paciente.

Para detectar las fallas en las intervenciones del terapeuta estudiamos deseos y defensas y su estado en los relatos y los actos de habla del paciente. Este estudio permite localizar los temas y escenas en que fracasan las defensas tanto funcionales como patológicas. El fracaso en las defensas puede darse en una o varias escenas relatadas y/o desplegadas. Luego de este estudio, aplicamos la categorización de los tipos de intervenciones y el análisis de los deseos y las defensas y su estado en los actos de habla del terapeuta. El estudio de los tipos de intervención que formula el terapeuta permite inferir si este tiene una o varias estrategias clínicas en cuanto a recabar información para detectar el foco problemático y la forma y/o el contenido de las intervenciones de sintonía, complementarias o de aquellas destinadas a establecer nexos. El estudio de las intervenciones y los actos de habla del terapeuta permite evaluar la pertinencia clínica de las intervenciones introductorias, de sintonía, de nexo o complementarias del terapeuta.

Luego evaluamos el tipo de intervención con el objetivo de inferir si el terapeuta perdió o nunca logró una orientación al formular las intervenciones introductorias, y cuán extensa fue su desorientación en la búsqueda del foco problemático; si bien omitió las intervenciones para sintonizar con el paciente, las formuló a destiempo o tendió a atribuir al paciente determinado estado cuando las manifestaciones del paciente indicaban otro; si erró en la elección del foco o, habiendo acertado en la elección, formuló intervenciones de nexo discordantes de lo que las manifestaciones del paciente indicaban $y$, finalmente, si realizó intervenciones complementarias con ejemplos contradictorios con lo que había expresado antes, síntesis en que omitía aspectos importantes de lo que previamente habían intercambiado, etc.

Una vez terminada esta evaluación, consideramos los actos de habla del terapeuta para inferir si desplegó escenas (verbales o no verbales) no acordes con los objetivos clínicos, como ser formular intervenciones de sintonía con voz extremadamente grave.

Si se detectan perturbaciones de contratransferencia por alguna de estas vías, evaluamos si las escenas desplegadas por el terapeuta tienen coincidencias con alguna escena central o menor relatada o desplega- 
da por el paciente o si aquel procura defenderse de su propia contratransferencia.

Reconsideramos en esta oportunidad estudios detallados con el ADL de ocho casos (Maldavsky et al., 2005; Maldavsky et al., 2006; Maldavsky et al., 2007; Maldavsky, Scilletta, Perez Zambón, Álvarez \& Sneiderman, 2011), en cuanto a deseos y defensas de los pacientes, intervenciones del terapeuta y escenas que el terapeuta desplegó en la sesión. Evaluamos los siguientes ítems: tipo de contratransferencia (transitoria o duradera); aspecto del discurso del terapeuta en que se ha inferido la mencionada contratransferencia; estímulo determinante del paciente; escena desplegada en la sesión; lugar del terapeuta en la escena desplegada y proceso psíquico desarrollado en el terapeuta.

Ejemplo de intervenciones en que el terapeuta ocupa el lugar de un personaje de la vida psíquica de la paciente

Corina consultó por los conflictos con el novio, quien la agredía ante sus amigos. Estos reaccionaban con críticas contra este y ella tendía a defenderlo en nombre del amor. Durante un período, la terapeuta pasó a criticar al novio del mismo modo que los amigos de la paciente.

Ejemplo de intervenciones en que el terapeuta no se centra en el foco de la sesión

Marisa fue remitida a tratamiento por sus reiterados cortes en la piel. En una sesión ella se refirió a su relación con el novio y con el padre. Respecto de la relación con el novio, tras varios momentos conflictivos, la situación se volvió más satisfactoria. Respecto de la relación con el padre, este comenzó a decirle frases absurdas con ojos de temor, la paciente tuvo una crisis de angustia y llanto y terminó arañándose la piel con las uñas. La terapeuta se centró en la relación con el novio, y no con el padre.

Ejemplo de intervenciones en que el terapeuta se defiende de su propia contratransferencia

María, una joven llamativa, contó diferentes situaciones de seducción hacia hombres en el trabajo. Además, tenía conflictos con su hermano, la madre y el novio, con un predominio de los sentimientos de injusticia. El terapeuta establecía insistentemente nexos entre los hechos relatados por la paciente y su tristeza; con intervenciones que parecían poco pertinentes y que corresponderían a una formación defensiva ante la contratransferencia erótica.

En las conclusiones consideramos cuatro puntos: enactment, procesos psíquicos del terapeuta, fallas clínicas, método.

Con respecto al primer punto, el estudio sugiere que la perturbación contratransferencial es un enactment; el terapeuta se ubica inadvertidamente en el lugar de un personaje de la vida psíquica del paciente, sin que esta actitud tenga un propósito clínico. Existen tres alternativas de un enactment perturbador: que el terapeuta se ubique en el lugar del paciente mismo, de un personaje conflictivo de la vida del paciente, o que desarrolle defensas ante ello. Esta perturbación de contratransferencia detectada en los actos de habla del terapeuta permite además inferir un deseo que el terapeuta no ha procesado. En todos los casos, la escena que el terapeuta despliega en la sesión está influida por los estímulos que el paciente promueve en el terreno verbal o no verbal.

Respecto del segundo punto (procesos psíquicos del terapeuta), proponemos inferir los deseos y defensas del terapeuta en los enactment inadvertidos, tomando en cuenta las escenas que despliega. En varios de los casos ocurre una rectificación por el terapeuta respecto de estos episodios de enactment o de su defensa frente a ellos, por lo cual se infiere que para el terapeuta eran parcialmente egodistónicos. Proponemos, además, que colocarse inadvertidamente en la posición de un personaje del paciente ocurre como consecuencia de una identificación del terapeuta $y$, a veces, de un mecanismo adicional, si ocurre también una alteración somática (somnolencia, taquicardia por rabia) que parece ser una introyección orgánica. En el enactment confluyen el aporte del paciente y algún sector en que el terapeuta es vulnerable.

Respecto de las fallas en el enfoque clínico, suelen ser transitorias, de extensión variable. Fue posible constatar que el terapeuta tenía dos estrategias clínicas, una pertinente y la otra no. Esta última, se conectaba con las perturbaciones contratransferenciales. Un factor determinante de estas perturbaciones de contratransferencia está constituido por los complejos no elaborados del terapeuta, pero también se agrega su formación, que interfiere en comprender determinados problemas y mantener una postura clínicamente pertinente. Adicionalmente, también interviene el hecho de que, si bien en lo inmediato focaliza correctamente el tema central en la sesión, el terapeuta omite otros temas que son detectables contextualmente (un aniversario, el día de la madre, etc.).

Respecto del método, el aporte se centra en los aspectos procedimentales del ADL. La secuencia de pasos es en todos los casos es la misma: a) Detección del fracaso de las defensas del paciente en los relatos y/o en los actos de habla, lo cual permite también estudiar el tipo de afecto dominante en el paciente, y evaluación de las intervenciones del terapeuta para detectar alguna falla duradera en el enfoque (por el contenido o la forma de sus intervenciones). b) Estudio de las escenas desplegadas por el terapeuta para inferir si desarrolló un enactment, y en caso afirmativo, en qué consiste este y cuál es el personaje que ocupa y que aparece en las escenas relatadas o desplegadas por el paciente. c) Detección de una rectificación del tera- 
peuta o de una defensa ante la tendencia a ocupar el lugar de un personaje de la vida psíquica del paciente. Además, estos procedimientos permiten detectar otros tipos de enactment que poseen un carácter más global y funcional, descriptos en la bibliografía, para lo cual se puede apelar solo al paso b recién mencionado.

\section{Estudio III: Deseos y valores en una publicidad tele- visiva (Maldavsky, 2014b)}

El objetivo es investigar deseos y valores expresados en un spot publicitario, en los terrenos verbal, visual, motriz y sonoro.

La muestra ("Mamá Lucchetti-Licuadora", duración: 37 segundos) fue segmentada en micro-unidades con coherencia interna, con la aclaración de su duración en términos de segundos (") y fracciones de estos ("'). De la muestra seleccionamos aquí estos segmentos:

1"4"': Mamá Lucchetti mira hacia un costado mientras bebe un sorbo de la taza con algo caliente. Luego de beber un sorbo, despliega una amplia sonrisa. La mirada de la madre es bizca y absorta.

2"6"': El hijo ingresa por el costado derecho de la madre a la cocina. Mientras avanza hacia ella dice: "Mamá, mamá, me comprás un robot que vi acá a la vuelta.... Su voz suena acelerada. Cuando finaliza la frase se detiene frente a su madre. En el instante en el que el niño dice "me comprás", Mamá Lucchetti tiene una mirada bizca hacia la dirección opuesta al lugar en que se encuentra el hijo, estira el brazo derecho hacia la licuadora y la enciende apretando el botón con un dedo. Luego, mientras mantiene apretado el botón, Mamá Lucchetti mira a su hijo. El sonido de la licuadora cubre la voz del niño y permanece sonando. En este momento aparece un primer plano de la licuadora, con lo cual se observa que está en funcionamiento sin contenido en su interior. A poco de empezar el sonido de la licuadora el niño calla y la madre quita el dedo del botón, con lo cual el aparato deja de sonar.

10"2"': El niño mira a la madre achicando los ojos y los brazos al costado del cuerpo. Expresa un breve sonido $y$, en el acto, la madre acciona la licuadora y comienza el sonido. El niño hace silencio y achica pronunciadamente los ojos mirando a su madre. Mamá Lucchetti mira a su hijo con una amplia sonrisa mientras continua el sonido de la licuadora.

12"3"': Mamá Lucchetti bizqueando va dirigiendo la mirada hacia el frente. Luego, ya de frente, con la mirada bizca sonríe ampliamente. El niño se encuentra a su lado mirándola.

Sucesivamente, se aplicaron los instrumentos del ADL para analizar la muestra a partir de los relatos; las imágenes visuales (en el terreno icónico y plástico); los programas gesticulares y los actos de habla y sonidos. Se intentó, además, articular los resultados de los es- tudios de modo coherente.

En términos de relato observamos varias secuencias, de las cuales consideraremos algunas. En la primera (unidad de análisis 1), la madre bebe algo de una taza, en un primer momento, y luego sonríe, en un segundo momento. En la segunda secuencia (unidad de análisis 2), en el primer momento, el niño irrumpe con su pedido; en un segundo momento, la madre, que ha dejado de sonreír, responde con el encendido de la licuadora; y en un tercer momento, se da un doble desenlace: el niño calla y la madre sonríe. En la séptima secuencia, en un momento inicial el niño, que mira a la madre, profiere un breve sonido; en un segundo momento, la madre acciona la licuadora; y en un tercer, momento el niño vuelve a mirar a su madre, quien a su vez sonríe. En la secuencia de cierre, un único momento se da de manera divergente entre una y otro: la madre mira sonriente al frente y el niño mira a su madre.

En la primera secuencia narrativa (solo de la madre), predomina un estado de equilibrio y paz, propio de O1, combinado con $\mathrm{O} 2$ (bienestar hogareño) y con LI (calma). LI, $\mathrm{O} 1$ y $\mathrm{O} 2$ se hallan en versión eufórica, con un predominio de $\mathrm{O} 2$ y LI. En la segunda secuencia narrativa, se quiebra este equilibrio por la irrupción del hijo con su pedido con voz acelerada. El análisis implica ya contar con dos perspectivas, la del niño y la de su madre. Desde la perspectiva del niño, el momento primero corresponde a $\mathrm{A} 2$ y $\mathrm{O} 2$ en versión eufórica (con el complemento de $\mathrm{A} 1$ y de $\mathrm{LI}$ ), mientras que el tercero expresa a $\mathrm{A} 2$ y $\mathrm{O} 2$ (y los deseos complementarios) en versión disfórica, lo cual se combina con el incipiente despertar de un interrogante ante un enigma (O1). En cambio, para la madre, el segundo momento corresponde a $\mathrm{O} 1$ y el tercero a $\mathrm{O} 2$ combinado con $\mathrm{LI}$, todos ellos en versión eufórica.

En la séptima secuencia narrativa, en el primer momento para el hijo prevalece 01 en versión disfórica, en el segundo momento predomina para la madre 01 combinado con LI en versión eufórica y en la tercera para el hijo predomina 01 en versión eufórica, mientras que en la madre predomina $\mathrm{O} 2$ combinado con $\mathrm{LI}$ en versión eufórica.

En la secuencia narrativa final, para la madre predomina $\mathrm{O} 2$ combinado con LI y para el niño, O1, ambos en versión eufórica.

En suma, en la historia predominan $\mathrm{O} 1$ (para el niño) y $\mathrm{O} 2$ combinado con LI (para la madre). Para ambos personajes tiene cierta relevancia el acercamiento, correspondiente a FU (en la secuencia narrativa 2, el niño se aproxima a la madre). También importa para la madre A2, ejemplificado en el acto de aferrar la taza que tiene en su mano izquierda; y el ruido (LI) para ambos, surgido de la licuadora, y que sugiere que para madre e hijo la voz del niño es su equivalente, un sonido monótono e intrusivo. En cuanto al momento inicial, 
corresponde a la situación a la que la madre aspira. En ella predomina $\mathrm{O} 2$ combinado con $\mathrm{O} 1$ (beber de la taza) y LI (un momento de calma). A lo largo del spot, ella pretende proteger este estado o retornar a él. Para la madre parece importante conciliar su amor al hijo y a la familia y su búsqueda de calma y de encuentro con una esencia. A su vez, el niño pasa desde la combinación entre demanda, aburrimiento y tendencia expulsiva, prevalentes en un comienzo, al desconcierto y el esfuerzo por develar el enigma contenido en la mente y mensaje materno, esfuerzo que culmina en logro tras varios momentos de decepción. El factor dinámico en el niño deriva de la transformación de $\mathrm{O} 2$ combinado con A1 y LI (en la demanda), a la versión disfórica y luego a la eufórica de $\mathrm{O}$.

En cuanto al análisis icónico de la imagen visual consiste en enfocar los contenidos representados y su conexión con una supuesta realidad, incluyendo las transformaciones de esta realidad (que tienen un carácter retórico). Observamos la contraposición entre las figuras de los personajes con rasgos caricaturescos (con transformaciones) y las del mobiliario (casi sin transformaciones), con lo cual las primeras cobran protagonismo. El inventario de los deseos detectados incluye FG, A2, A1, O2, O1, LI. Entre ellos, A1 tiene un valor menor y, del mismo modo, A2. FG, O2, $\mathrm{O} 1$ y LI tienen más relevancia. En cada personaje como unidad predomina $F G$, pero la secuencia de transformaciones, sobre todo ligadas a los estados afectivos y a la alimentación, destaca otros deseos: $\mathrm{O} 2$ para los estados afectivos y LI (y eventualmente O1), por la alimentación sin masticación y también por la astenia. Entre estas transformaciones, una corresponde a estados (O2 y LI) y la otra a acciones (LI y eventualmente O1).

En el análisis plástico se observan rasgos referidos a forma y color. Entre ellos, predominan $\mathrm{O} 1, \mathrm{O} 2$, A2 y FG, entre los cuales prevalece O2. Los recursos expresivos plásticos son más pobres que los icónicos, que parecen dominantes.

En cuanto al análisis de la motricidad, procuramos inferir los programas gesticulares centrales y complementarios en cada unidad de análisis. Cobra relieve la mirada de ambos personajes. Cuando se da una coordinación binocular, los movimientos corresponden a O1, a veces acompañado de A2 (cuando el personaje aspira a controlar o dominar la realidad), de FG (cuando trata de aparecer simpático) o de O2 (cuando expresa cariño). Cuando la mirada no conserva la coordinación binocular, expresa la falta de investidura del mundo sensorial en favor del mundo espiritual (O1) y de la calma (LI). Un mismo acto (mirar) puede tener dos valores, uno correspondiente al intercambio y el otro a procesos intra-psíquicos e intra-corporales, y admite una doble interpretación, en la cual a veces prevalece una de las dos posibles interpretaciones.
Seleccionamos algunas de las secuencias para mostrar aquí un análisis más detenido.

Primera secuencia:

- Mamá Lucchetti, sola en la cocina, mira a su costado derecho (O1).

- Sostiene una taza con un líquido humeante en la mano izquierda (A2).

- Se la lleva a los labios (O1).

- Bebe un sorbo de la taza (01).

- Deja de beber (01).

- Tiene una mirada bizca y absorta (O1, LI).

- Despliega una amplia sonrisa (O2, LI).

En la escena la madre desarrolla tres sub-programas gesticulares: el de la mirada, el de beber de la taza (descompuesto en tres acciones) y el de la sonrisa. El núcleo de la escena parece corresponder al estado de bienestar (O2). La posibilidad de empleo de la motricidad voluntaria al servicio del dominio (A2), la acción de beber (O1) y la mirada (O1 y LI) hacen de pasos intermedios, en que, a su vez, A2 queda al servicio de 01. Es posible que en la secuencia predomine el estado de bienestar afectivo (O2) combinado con el estado de calma (LI); desde este punto de vista, la secuencia podría ser el desarrollo de un procedimiento auto-calmante. Entre $\mathrm{O} 2$ y LI, el primero parece dominante.

\section{Segunda secuencia}

- Se observa una combinación de programas gesticulares entre madre e hijo y en cada personaje.

- El hijo ingresa a la cocina (FU).

- Mira a su madre (O1, A2).

- Dice: "mamá, mamá, me comprás un robot que vi acá a la vuelta" (A2 combinado con O2, A1 y LI).

- El niño se coloca frente a su madre (A2).

- Mamá Lucchetti dirige los ojos hacia el lado opuesto del lugar en que se encuentra el niño con una mirada bizca, cuando el niño dice "Me comprás" (O1, LI).

- La madre extiende el brazo derecho hacia la mesa (A2).

- La madre presiona el botón de la licuadora con el dedo índice de la mano derecha (O1).

- Mira al niño $(\mathrm{O} 1, \mathrm{~A} 2)$.

- El niño habla un momento superponiendo su voz con el sonido de la licuadora (A2).

- Luego calla (A2).

- El niño mira a la madre achicando los ojos $(\mathrm{O} 1, \mathrm{~A} 2)$. 
- La madre deja de apretar el botón (01).

- La madre baja el brazo derecho al costado del cuerpo (A2).

- El niño comienza de nuevo a hablar diciendo: "Perdón, te decía, si me comprás un robot..." (A2 combinado con $\mathrm{O} 2, \mathrm{~A} 1$ y LI).

- La madre extiende el brazo derecho hacia la mesa (A2).

- Enciende la licuadora (O1).

- El niño habla un momento superponiendo su voz con el sonido de la licuadora (A2).

- El niño calla (A2).

- Simultáneamente cierra pronunciadamente los ojos (O1, A2).

- Mamá Lucchetti suelta el botón de la licuadora pero mantiene el dedo sobre él (01).

- El niño mira a su madre achicando más aún los ojos (O1, A2).

En cuanto al niño, en esta secuencia es posible detectar dos programas gesticulares:

1. Comienza acercándose a la madre para exponer un pedido. En esta micro-escena el niño desarroIla al menos tres programas gesticulares: la mirada dirigida a su madre, el desplazamiento espacial y la articulación de palabras. El primero (mirada) corresponde a $\mathrm{O} 1$, combinado con $\mathrm{A} 2$; el segundo (acortamiento de las distancias con la madre) corresponde a FU, con A2 (dominio de la propia motricidad); y el tercero (pedido recurriendo a las palabras), corresponde a A2 y O2. Este último es el dominante, y los otros dos hacen de medio para lograr el objetivo de hablarle a la madre. Entre estos sub-programas, los dos primeros tienen un resultado eufórico y el último, uno disfórico (es obligado a callar). En cuanto a la fonación del niño cuando habla, el ritmo de la voz corresponde a $\mathrm{O} 2$ (impaciencia), A1 (aburrimiento) y LI (tendencia a descargarse)

2. La respuesta materna corresponde a un segundo programa gesticular que expresa un estado de desconcierto, expresado en el achicamiento de los ojos (O1 en versión disfórica).

En cuanto a la madre, se aprecian dos programas gesticulares: 1) Los ojos a veces se dirigen hacia el niño (O1 combinado con A2) y otras veces en la dirección opuesta y bizqueando (O1 combinado con LI) y, 2) el brazo se extiende (A2) y aprieta el botón que acciona la licuadora (O1). En el segundo programa gesticular, A2 aparece subordinado a $\mathrm{O} 1$. Ambos tienen un desenlace eufórico.
Por otra parte, los actos de habla son escasos. Las frases del niño se caracterizan por una insistencia en el pedido (O2 y A2). En cuanto a la madre, responde con un "no" en los hechos, y el niño tarda en descifrar este mensaje. Como acto de habla, el "no" de la respuesta materna es expresión de A2.

El rasgo fonológico materno de sorber corresponde a O1, y el sonido de la licuadora, a LI. Los rasgos fonológicos del niño en los momentos iniciales denotan impaciencia (O2), aburrimiento (A1), y un exceso de tensión que requiere descarga (LI).

Los resultados del estudio de los relatos y los desempeños motrices destacan para la madre el valor de LI y O2, por la mediación de O1. En cuanto al niño, parece central 01 . El estudio de los actos de habla agrega que cuando la madre recurre a la licuadora expresa con un instrumento (O1) y su ruido (LI) un "no" (A2) sin decirlo. Este matiz no altera la visión de conjunto.

A su vez, este resultado puede combinarse con el estudio de las imágenes visuales. En los componentes icónicos predominan $\mathrm{LI}, \mathrm{O} 1$ y $\mathrm{O} 2$, con el agregado de FG y en los plásticos, O2. El análisis fino de la motricidad de los personajes es coincidente con los resultados ya mencionados, y destaca el peso de 01.

Las conclusiones a partir de los resultados expuestos, pueden organizarse en los terrenos psicosocial y metodológico.

En relación a lo psicosocial, los deseos dominantes son: 1) para la madre, mantener o recuperar el equilibrio somático (LI), mantener o recuperar un contacto espiritual consigo mismo, o un acceso a una verdad (O1), mantener o recuperar el nexo tierno (O2), con los correspondientes valores: calma (LI), verdad (O1), amor (O2). $\mathrm{O} 1$ es un medio para alcanzar $\mathrm{LI}$ y O2, y O2 parece ser un requisito para mantener o recuperar $\mathrm{LI}$, y 2) para el hijo, salir del aburrimiento (A1), de la impaciencia (O2) y la necesidad de descarga (LI), luego remplazados por un afán cognitivo (O1) y el nexo amoroso (O2). Cuando el niño logra develar la incógnita, sale del aburrimiento, la impaciencia y de los estados de tensión sin descarga. Para el niño, sus valores iniciales son: amor (O2), justicia (A1) y ganancia (LI), y luego mutan hacia la prevalencia de la verdad (O1), que pasa a coordinar el conjunto.

La publicidad apunta a que cada destinatario (madre, hijo) perciba la situación desde la perspectiva propia y la del otro. El spot parece contener un mensaje: la forma de mantener la calma y el amor de la familia consiste en que, cuando el niño reclame con impaciencia, aburrimiento y necesidad de descarga, la madre promueva en él deseos cognitivos al generarle incógnitas.

Metodológicamente, hemos tomado diferentes decisiones en cuanto a segmentación y análisis de la muestra, que contienen un aporte al desarrollo de las 
investigaciones multidimensionales. En nuestro análisis han cobrado mayor relieve los resultados de los estudios con el ADL-SV icónico, el ADL-R y el ADL-M, quizá por los rasgos de la muestra.

\section{Comentario final}

En el estudio I apelamos a dos instrumentos (ADL-P y categorización de las intervenciones clínicas) para estudiar la función y los deseos en las intervenciones del terapeuta en la primera sesión con 20 pacientes. Por otro lado, en el estudio II recurrimos a tres instrumentos (ADL-R, ADL-AH, categorización de las intervenciones clínicas) con el objetivo de investigar una realidad compleja, específicamente, la perturbación contratransferencial del terapeuta por el influjo del paciente. Finalmente, en el estudio III apelamos a cinco instrumentos (ADL-R, ADL-AH, ADL-M, ADL-CF, ADLSV) para investigar otra realidad compleja, un spot publicitario. En este último estudio, la aplicación de los instrumentos es convergente, y en los dos primeros algunos instrumentos se aplican a los resultados de otros.

\section{Referencias}

Édeline, F., Klinkenberg, J. \& Minguet, Ph. (1993). Tratado del signo visual. Madrid: Cátedra.

Freud, S. (1915). Pulsiones y destinos de pulsión (Vol. 14). Buenos Aires: Amorrortu Editores.

Freud, S. (1926). Inhibición, síntoma y angustia (Vol. 20). Buenos Aires: Amorrortu Editores.

Greimas, A. (1973). En torno al sentido. Madrid: Fragua.

Maldavsky, D. (2013). ADL Algoritmo David Liberman. Un instrumento para la evaluación de los deseos y las defensas en el discurso. Buenos Aires: Paidós.

Maldavsky, D. (2014a). Un método de estudio de los deseos y las defensas en el componente icónico del signo visual (ADL-SV). Linguagem e Ensino, 17(1), 471-505 Recuperado de http://www.rle.ucpel.tche.br/index. $\mathrm{php/rle/article/view/1090}$

Maldavsky, D. (2014b). Deseos y valores en una publicidad televisiva. Un estudio de las imágenes, la motricidad, los sonidos y el discurso con el algoritmo David Liberman (ADL). Subjetividad y procesos cognitivos, 18(2), 122-153. Recuperado de http://ref.scielo.org/h9vp95
Maldavsky, D. (2014c). Instrumentos para el estudio de los deseos y las defensas en los desempeños motrices. Acta Psiquiátrica y Psicológica de América Latina, 60(1), 9-24. Recuperado de http://www.acta.org.ar/04-WebForms/frmVolumenes.aspx? DatVolumen=12\&Palabra $=$ Maldavsky\&IdAbonado $=$

Maldavsky, D. (2015a). Método de estudio de los deseos y las defensas en el componente plástico del signo visual (ADL-SV). Subjetividad y procesos cognitivos, 19(1), 149-173. Recuperado de http://ref.scielo.org/f9jnr9

Maldavsky, D. (2015b). Investigación empírica con el algoritmo David Liberman de la contratransferencia no declarada: método y aplicaciones. Investigaciones en psicología, 20(3), 61-75. Recuperado de http://www. psi.uba.ar/investigaciones/revistas/investigaciones/ indice/trabajos completos/anio20 3/maldavsky.pdf

Maldavsky, D., Aguirre, A., Alvarez, L., Bodni, O., Britti, A., Buceta, C., ... \& Angelis, C. (2005). Systematic research on psychoanalytic concepts and clinical practice: the David Liberman algorithm (DLA). Buenos Aires: UCES.

Maldavsky, D., Aguirre, A., Álvarez, L., Bodni, O., Britti, M., Buceta, C., ... \& Varela, R. (2007). La intersubjetividad en la clínica psicoanalítica. Investigación sistemática con el algoritmo David Liberman (ADL). Buenos Aires: Lugar.

Maldavsky, D., Aparaín, A., Berenstein, R., Bodni, O., Cusien, I., Falise, C., ... \& Tate de Stanley, C. (2007). El caso Z revisado. Clínica e investigación relacional, 1(1), 192-224. Recuperado de http://agorarelacional.es/Portals/0/ eJournalCeIR/V1N1/12_D Maldavsky Z\%20revisitado.pdf

Maldavsky, D., Scilletta, D., Perez Zambón, S., Álvarez, L. \& Sneiderman, S. (2011). Investigación de los aportes positivos y negativos de paciente y terapeuta a la alianza terapéutica. Un estudio con el algoritmo David Liberman (ADL). Subjetividad y procesos cognitivos, 15(1), 146-176. Recuperado de http://ref.scielo. org/bdn6rh

Maldavsky, D., Argibay, J., Scilletta, D., Rembado, J., De Simone, L., Otárola, J. \& García, H. (2016). Estudio de las intervenciones de un mismo terapeuta con 20 pacientes en la primera sesión. Subjetividad y procesos cognitivos, 20(1), 1852-7310. Recuperado de http://ref. scielo.org/vfvr4j 